$\overline{\text { Original }}$

\title{
Cleanability of Titanium and Stainless Steel Particles in Relation to Surface Charge Aspects
}

\author{
KAZUHIRO TAKAHASHI AND SATOSHI FUKUZAKI* \\ Industrial Technology Center of Okayama Prefecture, 5301 Haga, Okayama 701-1296, Japan
}

Received 13 July, 2007/Accepted 18 December, 2007

\begin{abstract}
The cleanability of titanium and 316 L stainless steel particles was studied in terms of their apparent surface charge density $\left(\sigma_{\mathrm{app}}\right)$. Bovine serum albumin (BSA) was used as the model fouling agent. Curves for the $\sigma_{\text {app }}$ of titanium and stainless steel particles showed the apparent points of zero charge ( $\mathrm{pzc}_{\mathrm{app}}$ ) of 4.6 and 8.5, respectively. Compared with the curve for the $\sigma_{\text {app }}$ of stainless steel, that of titanium was characterized by small positive and large negative $\sigma_{\text {app }}$ values. The isotherms for BSA adsorption and the saturation amount of BSA adsorbed on titanium and stainless steel depended largely on the intrinsic properties of BSA. In continuous cleaning in a plug-flow column fed by a $0.05 \mathrm{M} \mathrm{NaOH}$ solution, BSA was found to be faster desorbed from titanium than from stainless steel, and smaller amounts of BSA remaining after 120-min cleaning were observed on titanium. Kinetic analysis showed that the two first-order desorption rate constants, reflecting the rate of BSA desorption in the initial and later stages of cleaning, for titanium were respectively 1.7-fold and 1.3-fold higher than those values for stainless steel. It could be suggested that the better cleanability of titanium was probably due to the small binding strength of BSA on slightly negatively-charged titanium surfaces and due to their large negative $\sigma_{\text {app }}$ values under alkaline cleaning conditions.
\end{abstract}

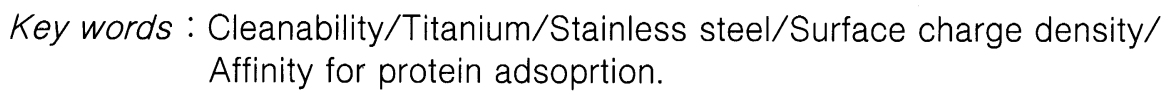

\section{INTRODUCTION}

In the food industry, the cleanliness and hygiene of food-processing equipment are very important issues. Materials used in the construction of the equipment must fulfill many requirements regarding corrosion resistance, nontoxicity, mechanical and thermal strength, longevity, and ease of fabrication (EHEDG, 1993). All product-contact surfaces of equipment must be resistant to the product, as well as to all cleaning and antimicrobial agents under operating conditions. In addition, the cleanability of equipment is a matter of great concern in hygienic plant operations. Austenitic stainless steels are widely used as construction materials for process

${ }^{*}$ Corresponding author. Tel : +81-86-286-9613, Fax : +8186-286-9630. plants in the biotechnology, pharmaceutical, and food industries. Their highly stain-resistant characteristics are due to the formation of chromium-rich oxide films, i.e., passive film, on the surfaces. Titanium, an unalloyed corrosion-resistant metal, also fulfills the above attributes and it is a commonly used material in severe environments such as heat-exchangers, and in medical implants and devices.

As well as stainless steels, titanium is known to spontaneously form an oxide layer on the outermost surface in the ambient. The outermost surfaces of the oxide layers on titanium and stainless steel are believed to be covered by hydroxyl groups (OH groups) formed by the chemisorption of water molecules (Boehm, 1971; Fukuzaki et al., 2003; Textor et al., 2001). The acid/base properties of surface $\mathrm{OH}$ groups on the oxide layer are strongly influenced by the degree of polarization of the oxygen coordinated to metal ions (M) in the bulk. The charge of the 
oxygen singly coordinated to metal ion $(-\mathrm{MOH})$ is still negative and it binds an additional proton, showing a basic character $\left(-\mathrm{MOH}_{2}{ }^{+}\right)$. The doubly coordinated oxygen is more polarized by metal ions and hence binds only one proton, then being uncharged $\left(-\mathrm{M}_{2} \mathrm{OH}^{\circ}\right)$. The doubly coordinated $\mathrm{OH}$ groups are not protonated, whereas they release protons depending on $\mathrm{pH}$, showing an acidic character $\left(-\mathrm{M}_{2} \mathrm{O}^{-}\right)$. Because of the presence of surface $\mathrm{OH}$ groups having different dissociation properties, the surface charge density and polarity of titanium and stainless steel surface vary widely as a function of the solution $\mathrm{pH}$. The surface charge of a solid surface is one of important factors determining the adsorption and desorption behaviors of food constituents, especially proteins (Fukuzaki, 2004; Norde, 1986; Wahlgren and Arnebrant, 1991). In spite of the stability of stainless steel, the susceptibility of its surfaces to protein adsorption and its cleanability are known to change depending on variations in the nature of passive films induced by physical and chemical treatments (Karlsson et al., 1999, 1998; Takahashi and Fukuzaki, 2006a, 2006b). On the other hand, although adsorption characteristics of proteins, oligopeptides, amino acids, and bacterial cells onto titanium surfaces have been studied by many researchers because of the biocompatibility of titanium (Brizzolara, 2002; Francois et al. 1997; Imamura et al., 2007; Klinger et al., 1997; MacDonald et al. 1998), the cleanability of the titanium surface has not been fully understood as compared with that of stainless steel.

The aim of this study is to compare the cleanability of titanium and stainless steel. To focus the discussion on physicochemical features of the adsorption and desorption behaviors, we used nonporous titanium particles and stainless steel particles, and bovine serum albumin (BSA) as the model fouling agent. The cleaning experiment was conducted in a plug-flow column fed by a $0.05 \mathrm{M} \mathrm{NaOH}$ solution, where the hydrodynamic forces are extremely low. The curve of BSA desorption was kinetically analyzed as a function of time, and the first-order desorption rate constants were compared. The cleanability of the titanium and stainless steel particles is discussed in relation to their surface charge aspects.

\section{MATERIALS AND METHODS}

\section{Materials and chemicals}

Nonporous titanium particles and $316 \mathrm{~L}$ stainless steel particles were obtained from Kojundo Chemical Laboratory Co., Ltd. (Saitama) and The Nilaco Corp. (Tokyo), respectively. The specific surface areas and mean diameters of titanium and stainless steel particles were $0.90 \mathrm{~m}^{2} / \mathrm{g}$ and ca. $10 \mu \mathrm{m}$, and $0.38 \mathrm{~m}^{2} / \mathrm{g}$ and ca. $9 \mu \mathrm{m}$, respectively. Before use, each of particles was washed in acetone, then in ethanol with sonication, and dried at $200^{\circ} \mathrm{C}$ for $4 \mathrm{~h}$. Crystalline BSA (Lot M9B4259) was purchased from Nacalai Tesque Inc. (Kyoto).

\section{Adsorption of BSA}

Adsorption of BSA was conducted at $40^{\circ} \mathrm{C}$ for $2 \mathrm{~h}$ in a $25-\mathrm{ml}$ vial containing $5 \mathrm{ml}$ of BSA solution ( 0.1 to $5 \mathrm{~g} / /$, in $10^{-3} \mathrm{M} \mathrm{KNO}_{3}$ ) and $0.56 \mathrm{~g}$ of titanium particles or $1.25 \mathrm{~g}$ of stainless steel particles (Fukuzaki et al., 2001). The surface area of both types of particles in a vial was approximately $0.5 \mathrm{~m}^{2}$. The amount of BSA adsorbed $(\Gamma)$ was determined as the sum of the amount of BSA removed and that of BSA still remaining on the particles $\left(S_{r}\right)$ after batchwise treatment with $0.1 \mathrm{M} \mathrm{NaOH}$ for $2 \mathrm{~h}$ with shaking (140 oscillations per min) as described previously (Fukuzaki et al., 2001). The value of $\Gamma$ was plotted against the equilibrium concentration of BSA $\left(C_{B S A}\right)$ after adsorption to obtain the adsorption isotherm.

\section{Cleaning experiment and kinetic analysis}

The cleaning experiment was conducted at $40^{\circ} \mathrm{C}$ in a plug-flow column $(4 \mathrm{~mm} \phi \times 50 \mathrm{~mm})$ fed by $0.05 \mathrm{M}$ $\mathrm{NaOH}$ solution (space time: $2 \mathrm{~min}$ ) for $120 \mathrm{~min}$ as described previously (Takahashi and Fukuzaki, 2003). The line velocity (LV) of the $\mathrm{NaOH}$ solution in the column was $0.33 \mathrm{~mm} / \mathrm{s}$, which corresponds to a laminar flow. After a 120-min cleaning operation, the amount of BSA remaining on titanium and stainless steel particles $\left(\Gamma_{r}\right)$ was determined. The curve of BSA desorption was obtained by plotting the logarithm of the amount of residual BSA against cleaning time, and analyzed by using the following model (Urano and Fukuzaki, 2002):

$$
\ln \Gamma=\ln \left\{\exp \left(\ln \Gamma_{0}^{t}-k^{t} t\right)+\exp \left(\ln \Gamma_{0}^{s}-k^{s} t\right)\right\}
$$

where $\Gamma$ is the amount of adsorbed BSA at any given time $t, \Gamma_{0}{ }^{t}$ and $\Gamma_{0}{ }^{s}$ (including $\Gamma_{\mathrm{r}}$ ) are the amounts of a faster-desorbing $B S A\left(B S A^{\dagger}\right)$ and a slowerdesorbing $\mathrm{BSA}\left(\mathrm{BSA}^{\mathrm{s}}\right)$ at zero time, respectively; $k$ and $k^{s}$ are the desorption rate constants of $\mathrm{BSA}^{\prime}$ and $\mathrm{BSA}^{s}$, respectively. The kinetic constants were calculated by a data-fitting procedure based on a nonlinear least-squares regression method (Urano and Fukuzaki, 2002).

\section{Analyses}

The apparent surface charge densities $\left(\sigma_{\text {app }}\right)$ of titanium and stainless steel particles or the net proton 
charge of BSA $\left(Z_{H^{+}}\right)$, and $\mathrm{pH}$ values for their apparent points of zero charge ( $p z c^{\prime}$ sapp ) were determined by potentiometric titration in the presence of $10^{-1} \mathrm{M}$ $\mathrm{KNO}_{3}$ (Fukuzaki et al., 2001). The chemical composition of the outermost surfaces of both kinds of particles was determined by $X$-ray photoelectron spectroscopy (XPS) as described previously (Takahashi and Fukuzaki, 2006a). The photoelectron spectra of Ti 2p, Fe 2p3/2, Cr 2p3/2, Ni 2p3/2, O 1s, and $C$ 1s were measured, where $2 p, 2 p 3 / 2$, and 1 s denote the spectroscopic levels of photoelectron peaks. The quantification of the elements was based on the area intensity and atomic percentage. BSA in solution or on stainless steel particles was determined by Lowry-Folin method as described previously (Fukuzaki et al., 2001).

\section{RESULTS AND DISCUSSION}

\section{Surface charge properties}

Figure 1 shows curves for the $\sigma_{\text {app }}$ of titanium and stainless steel particles, and for the $Z_{\mathrm{H}^{+}}$of BSA as a function of $\mathrm{pH}$. The pzc'sapp, the $\mathrm{pH}$ giving the acidbase equivalence point, of titanium, stainless steel, and BSA were found to be $4.6,8.5$, and 5.2 , respectively. Compared with the curve for the $\sigma_{\text {app }}$ of stainless steel, the curve for the $\sigma_{\text {app }}$ of titanium was characterized by small positive $\sigma_{\text {app }}$ values and large negative $\sigma_{\text {app }}$ values over the $\mathrm{pH}$ range of 3 to 10 (Fig. 1A). It has been reported that the isoelectric point (IEP) and $\mathrm{pzc}_{\text {app }}$ of titanium and titanium dioxide $\left(\mathrm{TiO}_{2}\right)$ ranged between 4.4 and 6.2 (Carre et al., 1992; Fukuzaki et al., 1996; Parks, 1965; Textor et al., 2001). Stainless steel showed large positive $\sigma_{\text {app }}$ values in the acidic and neutral $\mathrm{pH}$ regions and small $\sigma_{\text {app }}$ values in the alkaline $\mathrm{pH}$ region of 9 to 10 . BSA is also a versatile polyelectrolyte and it has positive and negative $Z_{\mathrm{H}^{+}}$values on the acidic and basic sides of $\mathrm{pH} 5.2$ (Fig. 1B).

Figure 2 shows the XPS Ti $2 p$ and $O 1$ spectra of titanium particles. The peak of the $\mathrm{Ti} 2 \mathrm{p} 3 / 2$ spectrum
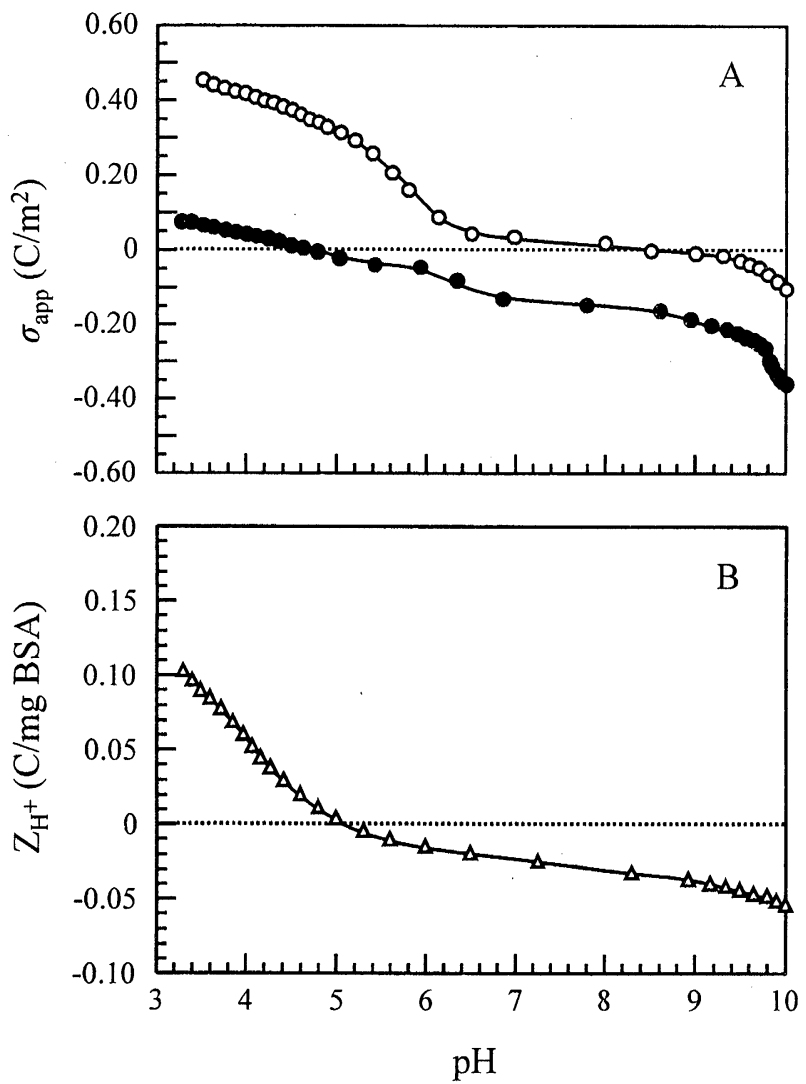

FIG. 1. Curves for the $\sigma_{\text {app }}$ of titanium and stainless steel particles (A) and for $Z_{\mathrm{H}^{+}}$of BSA (B). Potentiometric titration was conducted in $10^{-1} \mathrm{M} \mathrm{KNO}_{3}$ solution. Symbols: (A) , titanium; $O$, stainless steel; (B) $\triangle$, BSA.

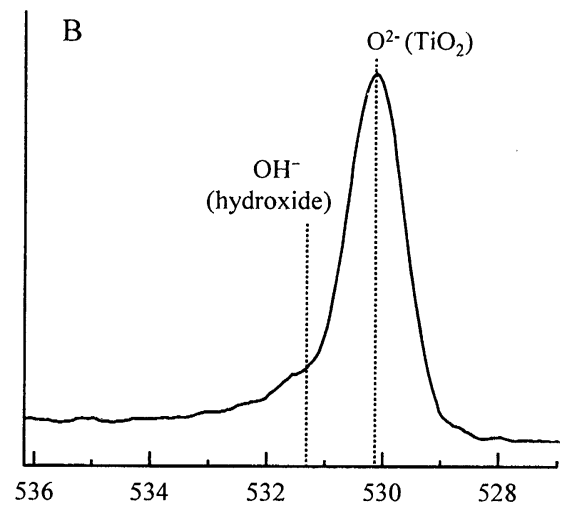

Binding energy $(\mathrm{eV})$

FIG. 2. XPS spectra of $T i 2 p$ and $O$ 1s of titanium particles. Titanium particles were molded into a plate by compression ( $20 \mathrm{MPa}, 2 \mathrm{~min}$ ) and analyzed by using monochromatized $\mathrm{AlK}_{\alpha}$ radiation at $300 \mathrm{~W}(12 \mathrm{kV})$. 
was observed at the binding energy of 458.9 which coincides with $\mathrm{Ti}^{4+}$-oxide $\left(\mathrm{TiO}_{2}\right)$ at $459 \pm 0.2 \mathrm{eV}$ (Vörös et al., 2001). The peak of the $O$ 1s spectrum was observed at the binding energy of $530.2 \mathrm{eV}$, which is in good agreement with the reported value of $530.0 \pm 0.2 \mathrm{eV}$ for $\mathrm{O}^{2-}$ (Rossi et al., 2000). These results confirm the presence of the $\mathrm{TiO}_{2}$ layer on the surface of titanium. It has been demonstrated that the peaks of the $\mathrm{Fe} 2 \mathrm{p} 3 / 2$ and the $\mathrm{Cr} 2 \mathrm{p} 3 / 2$ spectra of stainless steel particles (heated at $200^{\circ} \mathrm{C}$ ) were approximately fitted with $\mathrm{Fe}^{3+}$-oxide $\left(\mathrm{Fe}_{2} \mathrm{O}_{3}\right)$ at $710.8 \pm$ $0.1 \mathrm{eV}$ and with $\mathrm{Cr}^{3+}$-oxide $\left(\mathrm{Cr}_{2} \mathrm{O}_{3}\right)$ at $576.6 \pm 0.1 \mathrm{eV}$, respectively, and that the $\mathrm{Fe} / \mathrm{Cr}$ ratio of the stainless steel was approximately 1:1 (Takahashi and Fukuzaki, 2006a). In general, the acidity of metal oxides increases with the charge/radius ratio, $Z_{+} / R$, of the metal cations (Parks, 1965), where $Z_{+}$is the ionic charge of the cation, $R$ is the sum of $2 r_{0}$ and $r_{+}, r_{0}$ and $r_{+}$are the radii of oxygen and the cation, respectively. Assuming that the coordination number of $\mathrm{Ti}^{4+}, \mathrm{Fe}^{3+}$, and $\mathrm{Cr}^{3+}$ is 6 and these metal ions are surrounded by six oxygens, the $Z_{+} / R$ values of $\mathrm{Ti}^{4+}, \mathrm{Fe}^{3+}$, and $\mathrm{Cr}^{3+}$ are calculated to be approximately $11.7,8.96$, and $8.77 \mathrm{~nm}^{-1}$, respectively (Jia, 1991). The more acidic nature of titanium particles is consistent with the higher $Z_{+} / R$ of $\mathrm{Ti}^{4+}$ than $\mathrm{Fe}^{3+}$ and $\mathrm{Cr}^{3+}$.

\section{Adsorption of BSA}

Adsorption of BSA onto titanium and stainless steel particles was conducted over the $\mathrm{pH}$ range of 3.0 to 7.5. Even when BSA had the same type of net charge as that of both types of particles, the adsorption of BSA occurred spontaneously. When all the BSA-

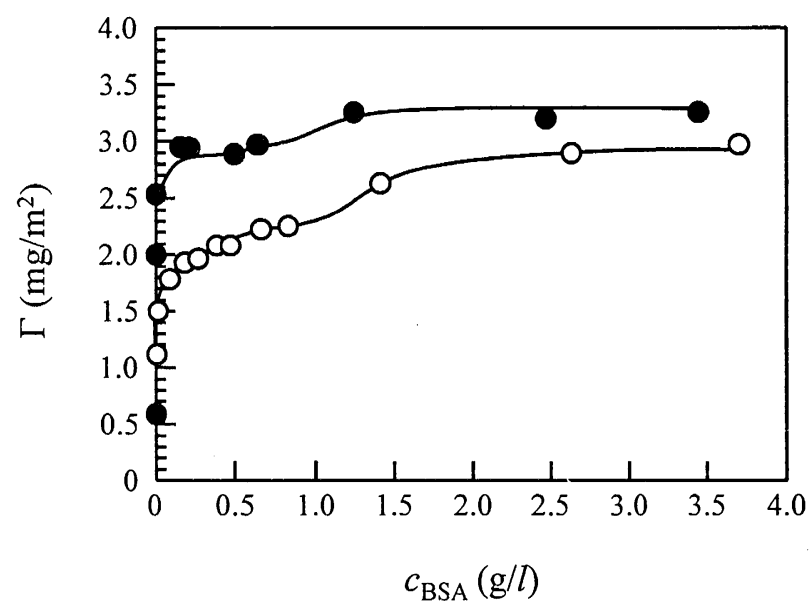

FIG. 3. Isotherms for BSA adsorption on the titanium and stainless steel particles at $40^{\circ} \mathrm{C}$ and at $\mathrm{pH} 5.0$. The adsorption experiment was conducted in the presence of $10^{-3} \mathrm{M}$ $\mathrm{KNO}_{3}$ with reciprocal shaking for $2 \mathrm{~h}$ (140 oscillations per $\mathrm{min})$. Symbols: ${ }^{-}$titanium; $\bigcirc$, stainless steel. adsorbed titanium and stainless steel particles obtained were immersed in $10^{-3} \mathrm{M} \mathrm{KNO}_{3}$ solution at 40 ${ }^{\circ} \mathrm{C}$ for $2 \mathrm{~h}$, no desorption of BSA occurred, indicating that the adsorption of BSA on both types of particles was irreversible.

Figure 3 shows the typical isotherms for BSA adsorption on the titanium and stainless steel particles at $40^{\circ} \mathrm{C}$ and at $\mathrm{pH}$ 5.0. Each of the isotherms on both kinds of particles exhibited a steep initial slope along the ordinate and a plateau (i.e., saturation value) in higher $C_{B S A}$ regions. Such saturation curves of isotherms were observed over the $\mathrm{pH}$ range of 3.0 to 7.5 (data not shown). In addition, the existence of a small "step" in each of the isotherms was observed, which is characteristic of the isotherm for BSA adsorption onto solid surfaces (Elgersma, 1990; Fair and Jamieson, 1980; Urano and Fukuzaki, 2000). There is a general agreement that such steps seem to indicate the presence of different orientations, e.g., side-on and end-on configurations, for the adsorbed protein molecules rather than the formation of a second layer (Elgersma, 1990; Fair and Jamieson, 1980; Norde and Lyklema, 1978).

Figure 4 shows the saturation amount of BSA adsorbed $\left(\Gamma_{\text {sat }}\right)$ on titanium and stainless steel particles as a function of $\mathrm{pH}$. The $\Gamma_{\text {sat }}$ values on both types of particles ranged between 1.7 and $3.4 \mathrm{mg} / \mathrm{m}^{2}$, which were less than a monolayer coverage of BSA adsorbed (Norde and Giacomelli, 2000). Considering the irreversibility of adsorption, it is suggested that BSA molecules are directly adsorbed on both kinds of particles within one monolayer coverage. The maximum values of the $\Gamma_{\text {sat }}$ on titanium and stainless steel were 3.4 and $3.1 \mathrm{mg} / \mathrm{m}^{2}$, respectively. The adsorption maxima on titanium and stainless steel were obtained

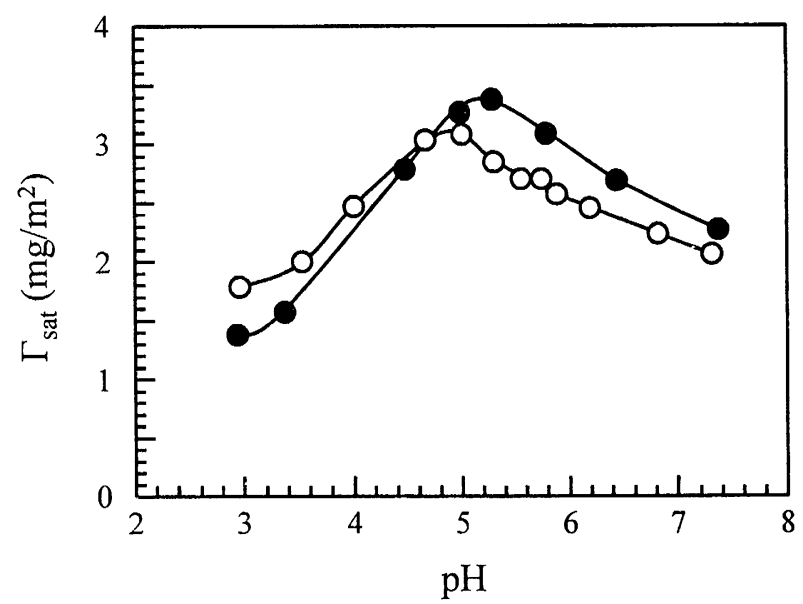

FIG. 4. The $\mathrm{pH}$-dependence of $\Gamma_{\text {sat }}$ values for titanium and stainless steel particles over the $\mathrm{pH}$ range of 3 to 7.5 . For experimental conditions, see the legend for Fig. 3. Symbols: titanium; $\bigcirc$, stainless steel. 
at around the $\mathrm{pzC}_{\text {app }}$ of $\mathrm{BSA}$, i.e., 5.2, although the surface charge properties of titanium and stainless steel differ from each other. The occurrence of an adsorption maximum in the $\mathrm{pzc}_{\text {app }}$ region of protein is commonly found on various solid surfaces (Fukuzaki et al., 1995, 1996; Koutsoukos et al., 1983; Norde and Lyklema, 1978). A small $Z_{\mathrm{H}^{+}}$of BSA can cause the contraction of the molecule and reduce the lateral electrostatic repulsion between adjacent BSA molecules, thereby resulting in an adsorption maximum at around the $\mathrm{pzC}_{\mathrm{app}}$ of $\mathrm{BSA}$. It is conceivable that the $Z_{\mathrm{H}^{+}}$of BSA is a more important factor for determining the $\Gamma_{\text {sat }}$ value rather than the nature of the metal surfaces.

The $S_{r}$ values after $0.1 \mathrm{M} \mathrm{NaOH}$ treatment of BSAadsorbed titanium and stainless steel particles were $0.31 \pm 0.09$ and $0.35 \pm 0.19 \mathrm{mg} / \mathrm{m}^{2}$, respectively. In the only case of BSA-adsorbed stainless steel, there was a slight tendency that the $S_{r}$ values for the BSA adsorbed at acidic $\mathrm{pHs}$ (ca. $0.38 \mathrm{mg} / \mathrm{m}^{2}$ ) were relatively larger compared with those adsorbed at alkaline $\mathrm{pHs}$ (ca. $0.32 \mathrm{mg} / \mathrm{m}^{2}$ ).

\section{Cleanability of BSA-adsorbed titanium and stain- less steel particles}

In order to facilitate the comparison of the cleanability, the $\Gamma_{0}$ values for titanium and stainless steel particles were almost unified at ca. $2.9 \mathrm{mg} / \mathrm{m}^{2}$, and adsorption of BSA occurred at $\mathrm{pH} 5.2$ because the acid-base equilibrium on BSA molecules is balanced in the solution. Figure 5 compares curves characterizing BSA desorption from titanium and stainless steel particles during cleaning with $0.05 \mathrm{M} \mathrm{NaOH}$ solution. It was clearly observed that the rate and the effi-

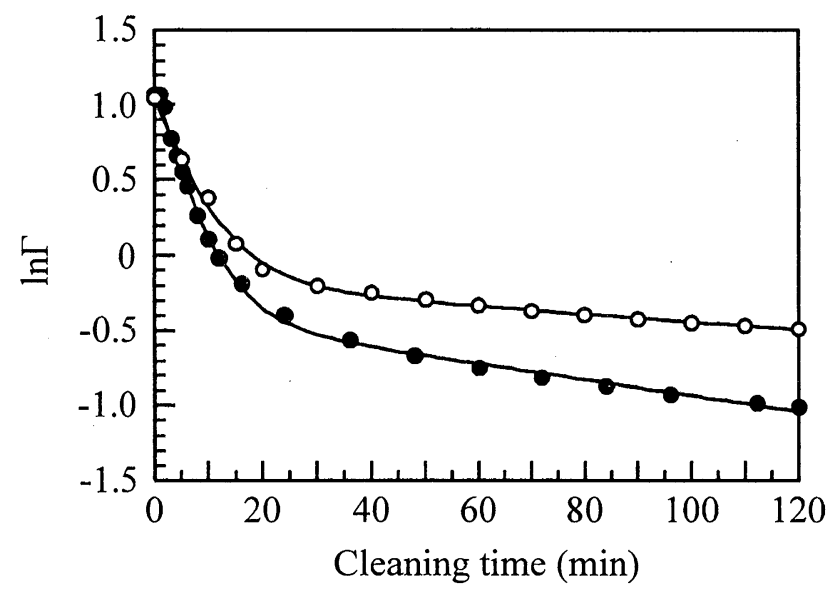

FIG. 5. Curves characterizing BSA desorption from titanium and stainless steel particles during cleaning with $0.05 \mathrm{M}$ $\mathrm{NaOH}$. The cleaning experiment was conducted at $40^{\circ} \mathrm{C}$ in a plug-flow stainless steel column installed vertically. Symbols: $\mathbf{O}$, titanium; $\bigcirc$, stainless steel.
TABLE 1. First-order desorption rate constants ${ }^{a}$ of eq. 1 derived from the data-fitting procedure and the $\Gamma$, values ${ }^{a}$ on titanium and stainless steel particles.

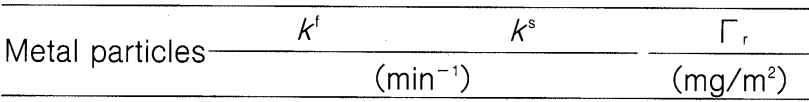

Stainless steel $0.093 \pm 0.0290 .0052 \pm 0.0003 \quad 0.61 \pm 0.02$

$\begin{array}{llll}\text { Titanium } & 0.16 \pm 0.01 & 0.0065 \pm 0.0019 & 0.35 \pm 0.01\end{array}$

a Mean value \pm standard deviation of the triplicated experiments.

Cleaning was conducted in a plug-flow column at $40^{\circ} \mathrm{C}$ by feeding $0.05 \mathrm{M} \mathrm{NaOH}$.

ciency of BSA desorption were higher on titanium than on stainless steel. The solid lines in Fig. 5 were derived from the computer analysis using eq. 1 based on a nonlinear regression method. The estimated constants of eq. 1 for titanium and stainless steel particles curves are summarized in Table $1(n=3)$. The $k^{t}$ and $k^{s}$ values for titanium were approximately 1.7 fold and 1.3-fold as large as those for stainless steel, respectively. The $\Gamma$, value was also smaller on titanium $\left(0.35 \mathrm{mg} / \mathrm{m}^{2}\right)$ than on stainless steel $(0.61 \mathrm{mg} /$ $\left.\mathrm{m}^{2}\right)$. These results indicate that the cleanability of titanium is superior to that of stainless steel. Under cleaning conditions used in this study, the hydrodynamic forces and shearing stresses in the plug-flow column were negligible ( $\mathrm{LV}=0.33 \mathrm{~mm} / \mathrm{s}$ ). Apparently, the cleanability of titanium particles depends both on the binding strength of BSA on titanium surfaces, and on the susceptibility of their surfaces to the cleaning action of the $\mathrm{NaOH}$ solution.

\section{Factors influencing the cleanability}

When a protein approaches a hydrophilic solid surface by diffusion and their diffuse electrical double layers are overlapped, the net force of attraction is determined mainly by the summation of van der Waals forces and electrostatic forces. During this initial stage, the protein is attached on the solid surface in a reversible fashion and does not still reach a dynamic adsorption equilibrium. After being adsorbed on a solid surface, the protein undergoes structural deformation to optimize binding, depending on time, the nature of solid surface, and surface coverage (Norde, 1986; Urano and Fukuzaki, 2000; Wahlgren and Arnebrant, 1991). A structural deformation of the protein to a flattened configuration allows a multiple attachment with more interaction points, thereby causing irreversible adsorption. The short-range forces involved in the irreversible adsorption are ionion interactions, dipole-dipole interactions, hydrogen bonding, coordination bonding, and hydrophobic interactions. The extent of structural deformation and the binding strength of the protein depend on the 
number of attachments and type of interactions between the protein and the solid surface.

It is known that carboxyl groups $\left(-\mathrm{COO}^{-}\right)$on amino acid residues of peptides and proteins, including BSA, play an important role in the irreversible adsorption on stainless steel surfaces through electrostatic interaction and possibly nonelectrostatic interaction such as coordination bonding (Fukuzaki et al., 1998; Sakiyama et al., 1999; Takahashi and Fukuzaki, 2006a; Urano and Fukuzaki, $2000,2002)$. The large number of carboxyl groups interacting with a metal oxide surface results in the strong binding of BSA to the metal oxide surface and in a low-rate desorption of BSA during alkali cleaning (Urano and Fukuzaki, 2000). In addition, it has been pointed out that organic acids can be adsorbed on metal oxide surfaces by direct coordination of one or more oxygen atoms of the carboxyl groups to the metal ions of the solid surface, replacing the singly coordinated surface $\mathrm{OH}$ groups $(-\mathrm{MOH}$ or $\mathrm{MOH}_{2}^{+}$), i.e., inner sphere complexes (Filius et al., 1997). This type of interaction gives a large binding strength per bond. It is conceivable that some of the carboxyl groups on BSA involved in adsorption might be bound to stainless steel surfaces via inner sphere complexation. In this study, there was a tendency that the $S_{r}$ value on stainless steel surfaces were relatively larger compared with those on titanium or when BSA was adsorbed on large-positively charged surfaces in an acidic milieu. These findings suggest that the binding strength of BSA depends largely on the magnitude of forces of interaction between the carboxyl groups on BSA and positively charged $\mathrm{OH}$ groups ($\mathrm{MOH}_{2}{ }^{+}$) on metal surfaces although details about the type of interaction have not been clarified. It is presumed that BSA can strongly interact with stainless steel surfaces having a large $\sigma_{\text {app }}$ value (e.g., +0.30 $\mathrm{C} / \mathrm{m}^{2}$ at $\mathrm{pH}$ 5.2) via the large number of carboxyl groups, leading to the extensive structural deformation of the adsorbed molecule. In any case, the flattened configuration, similar to an end-on configuration, of BSA allows a large binding strength. On the other hand, when the BSA adsorbed on solid surfaces constitutes less than one monolayer of coverage, a strong interaction does not always result in a large amount adsorbed because the flatted configuration of BSA occupies a large area per molecule on solid surfaces. In fact, titanium exhibited a highaffinity isotherm and the larger maximum $\Gamma$ sat value than stainless steel particles (Figs. 3 and 4).

The $\mathrm{pH}$ for the $\mathrm{pzc}_{\mathrm{app}}$ of titanium was 4.7 and titanium surfaces were more acidic in nature than stainless steel surfaces (Fig. 1). Titanium surfaces carried only a slight negative $\sigma_{\text {app }}\left(\mathrm{ca} .-0.03 \mathrm{C} / \mathrm{m}^{2}\right)$ at $\mathrm{pH}$
5.2 , indicating that at this $\mathrm{pH}$ the relative number of negatively charged $\mathrm{OH}$ groups $\left(-\mathrm{Ti}_{2} \mathrm{O}^{-}\right)$were larger than that of positively charged $\mathrm{OH}$ groups $\left(-\mathrm{TiOH}_{2}{ }^{+}\right)$. In previous studies on the adsorption of peptide and proteins on titanium (Brizzolara, 2002; Imamura et al., 2007; Textor et al., 2001), the interactions have been described successfully in terms of electrostatic interactions between negatively charged titanium surfaces $\left(-\mathrm{Ti}_{2} \mathrm{O}^{-}\right)$and protonated amino groups $\left(-\mathrm{NH}_{3}{ }^{+}\right)$on amino acid residues on the basic side of the $\mathrm{pzc}_{\mathrm{app}}$ of titanium, or between positively charged titanium surfaces $\left(-\mathrm{TiOH}_{2}{ }^{+}\right)$and dissociated carboxyl groups $\left(-\mathrm{COO}^{-}\right)$on amino acid residues on the molecule on the acidic sides of the pzC $_{\text {app }}$ of titanium. In this connection, in our previous study (Fukuzaki et al., 1996), we measured the $\mathrm{PZC}_{\text {app }}$ of $\mathrm{BSA}$ in the adsorbed state on negatively charged silica $\left(-0.04 \mathrm{C} / \mathrm{m}^{2}\right)$ using potentiometric titration and showed that part of the carboxyl groups on BSA were oriented toward the contact region at the silica surface. This indicates that the carboxyl groups on BSA might also contribute to the adsorption on the negatively charged silica surface via hydrogen bonding, where negative charges on BSA and silica are compensated by protons or cations. Judging from these findings, it is thought that at $\mathrm{pH}$ 5.2, BSA was probably adsorbed on slightly negatively-charged titanium via both protonated amino groups and only the limited number of carboxyl groups on the molecules. The interaction between the negatively charged titanium and protonated amino groups is not as strong as that between the positively charged titanium and dissociated carboxyl groups because of the lower polarity of amino groups. This is true of the hydrogen bonding between the neutral forms of carboxyl groups and $\mathrm{OH}$ groups on metal surfaces. Therefore, there is not such a strong interaction between BSA and titanium surfaces as there is between BSA and stainless steel. A weak interaction leads to little structural deformation of BSA molecule. In other words, this weak interaction might be responsible for the excellent biocompatibility of the titanium surfaces. It is reasonable that BSA molecules weakly adsorbed on negatively charged titanium surfaces could be desorbed faster and more effectively than on positively charged stainless steel surfaces during alkali cleaning (Fig. 5).

Another factor influencing the susceptibility of titanium surfaces to the cleaning action of the $\mathrm{NaOH}$ solution is the large negative $\sigma_{\text {apo }}$ values of titanium under the alkaline $\mathrm{pH}$ region (Fig. 1). Under $\mathrm{OH}^{-}$ concentrations, the BSA molecule is also negatively charged and swollen by the intracellular electrostatic repulsion. During the course of alkali cleaning, a 
repulsive force between solid surfaces and adsorbed $\mathrm{BSA}$ is one of the important factors accelerating the removal of BSA at solid-liquid interfaces (Fukuzaki et al., 2006; Takahashi and Fukuzaki, 2006b). The prevalence of surface $\mathrm{OH}$ groups (i.e., hydrophilicity) on titanium particles and their acidic nature imply that $\mathrm{OH}^{-}$ions can have easy access to the titanium surfaces and make their surfaces more negative. Therefore, titanium surfaces might exert a strong repulsive force against negatively-charged BSA. The hydrophiliic and acidic natures of the titanium surface are likely to be responsible for its better cleanability compared with stainless steel.

\section{REFERENCES}

Boehm, H. P. (1971) Acidic and basic properties of hydroxylated metal oxide surfaces. Discuss. Faraday Soc., 52, 264-277.

Brizzolara, R. A. (2002) Adsorption of alginic acid to titanium investigated using $\mathrm{x}$-ray photoelectron spectroscopy and atomic force microscopy. Surf. Interface Anal., 33, 351-360.

Carre, A., Roger, F., and Varinot, C. (1992) Study of acid/ base properties ofd oxide, oxide glass, and glassceramic surface. J. Colloid Interface Sci., 154, 174-183.

Elgersma, A. V., Zsom, R. L. J., Norde, W., and Lyklema, J. (1990) The adsorption of bovine serum albumin on positively and negatively charged polystyrene latices. J. Colloid Interface Sci., 138, 145-156.

European Hygienic Equipment Design Group (1993) Hygienic equipment design criteria. Trends Food Sci. Technol., 4, 225-229.

Fair, B. D. and Jamieson, A. M. (1980) Studies of protein adsorption on polystyrene latex surfaces. J. Colloid Interface Sci., 77, 525-534.

Filius, J. D., Hiemstra, T, and Van Riemsdijk, W. H. (1997) Adsorption of small weak organic acids on goethite: modeling of mechanisms. J. Colloid Interface Sci., 195, 368380.

François, P., Vaudaux, P., Taborelli, M., Tonetti, M., Lew. D. P., and Descouts, P. (1997) Influence of surface treatments developed for oral implants on the physical and biological properties of titanium. Clin. Oral Impl. Res., 8 , 217-225

Fukuzaki, S. (2004) Interaction between protein and metal oxide surfaces and its relevance to the cleanability. Bokin Bobai, 32, 203-213 (in Japanese).

Fukuzaki, S., Takehara, A., and Takahashi, K. (2006) Role of a surfactant in caustic alkali cleaning of polyethylene terephthalate surfaces fouled with organic substances. Biocontrol Sci., 11, 167-174.

Fukuzaki, S., Takehara, A., Takahashi, K., Hiramatsu, M., and Koike, K. (2003) Control of the surface charge and improved corrosion resistance of stainless steel by the combined use of gaseous ozone and heat. J. Surface Finish. Soc. Jpn., 54, 1034-1042.

Fukuzaki, S., Urano, H., and Hiramatsu, M. (1998) Variation in the surface charge of stainless steel by surface treatment: role of surface hydroxyl groups. J. Surface Finish. Soc. Jpn., 49, 915-916.

Fukuzaki, S., Urano, H., Hiramatsu, M., and Takehara, A. (2001). Effect of ozone on the surface charge and cleanability of stainless steel. Biocontrol Sci., 6, 87-94.

Fukuzaki, S., Urano, H., and Nagata, K. (1995) Adsorption of protein onto stainless-steel surfaces. J. Ferment. Bioeng., 80, 6-11.

Fukuzaki, S., Urano, H., and Ngata, K. (1996) Adsorption of bovine serum albumin onto metal oxide surfaces. J. Ferment. Bioeng., 81, 163-167.

Imamura, K., Kawasaki, Y., Nagayasu, T., Sakiyama, T., Nakanishi, K. (2007) Adsorption characteristics of oligopeptides composed of acidic and basic amino acids on titanium surface. J. Biosci. Bioeng., 103, 7-12.

Jia, Y. Q. (1991) Crystal radii and effective ionic radii of the rare earth ions. J. Solid State Chem., 95, 184-187.

Klinger, A. Steinberg, D., Kohavi, D., and Sela, M. N. (1997) Mechanism of adsorption of human albumin to titanium in vitro. J. Biomed. mater. Res., 36, 387-392.

Karlsson, C. A.-C., Wahlgren, M. C., Olsson, C.-O. A., and Trägårdh, A. C. (1999) Detergent-induced removal of $\beta$-lactoglobulin from stainless steel particles as influenced by surface pretreatment. J. Colloid Interface Sci., 220, 471-473.

Karlsson, C. A.-C., Wahlgren, M. C., and A. C. Trägårdh (1998) Some-related aspects of the cleaning of new and reused stainless-steel surfaces fouled by bprotein. Int. Dairy J., 8, 925-933.

Koutsoukos, P. G., Norde, W., and Lyklema, J. (1983) Protein adsorption onn hematite $\left(\alpha-\mathrm{Fe}_{2} \mathrm{O}_{3}\right)$ surfaces. $J$. Colloid Interface Sci., 954, 385-397.

MacDonald, D. E., Markovic, B., Allen, M., Somasundaran, P., and Boskey, A. L. (1998) Surface analysis of human plasma fibronectin adsorbed to commerecially pure titanium materials. J. Biomed. mater. Res., 41, 120-130.

Norde, W. (1986) Adsorption of proteins from solution at the solid-liquid interface. Adv. Colloid Interface Sci., 25, 267-340.

Norde, W., and Giacomelli, C. E. (2000) BSA structural changes during homomolecular exchange between the adsorbed and the dissolved states. J. Biotechnol., 79, 259-268.

Norde, W. and Lyklema, J. (1978) The adsorption of human plasma albumin and bovine pancreas ribonuclease at negatively charged polystyrene surfaces. I. Adsorption isotherms. Effect of charge, ionic strength, and temperature. J. Colloid Interface Sci., 66, 257-265.

Parks, G. A. (1965) The isoelectric points of solid oxides, solid hydroxides, and aqueous hydroxo complex systems. Chem. Rev., 65, 177-198.

Rossi, A., and Elsener, B., Hähner, G., Textor, M., and Spencer, N. D. (2000) XPS, AES and ToF-SIMS investigation of surface films and the rple of inclusions on pitting corrosion in austenitie stainless steels. Surf. Interface Anal., 29, 460-467.

Sakiyama, T., Tanino, K., Urakawa, M., Imamura, K., Takahashi, T., Nagai, T., and Nakanishi, K. (1999) Adsorption characteristics of tryptic fragments of bovine $\beta$-lactoglobulin on a stainless steel surface. J. Biosci. Bioeng., 88, 536-541.

Takahashi, K., and Fukuzaki, S. (2003) Kinetic approach to 
the nonlinear curve of bovine serum albumin desorption from stainless steel surfaces. Biocontrol Sci., 8, 111-117.

Takahashi, K., and Fukuzaki, S. (2006a) Cleanability of stainless steel surfaces as influenced by heat treatment. Biocontrol Sci., 11, 61-68.

Takahashi, K., and Fukuzaki, S. (2006b) Improvement of cleanability of stainless steels with various surface chemical composition by gaseous ozone. J. Surface Finish. Soc. Jpn., 57, 290-295.

Textor, M., Sittig, C., Frauchiger, V., Tosatti, S., and Brunette, D. M. (2001) Properties and biological significance of natural oxide films on titanium and its alloys. In Titanium in Medicine: material science, surface science, engineering, biological responses and medical applications (Brunette, D. M., Tengvall, P), pp. 171-230, Springer Verlag, Heidelberg and Berlin.
Urano, H., and Fukuzaki, S. (2000) Conformation of adsorbed bovine serum albumin governing its desorption behavior at alumina-water interfaces. J. Biosci. Bioeng., 90, 105-111.

Urano, H., and Fukuzaki, S. (2002) Kinetic study of desorption of two species of bovine serum albumin from alumina during alkali elution process. J. Colloid Interface Sci., 252, 284-289.

Vörös, J., Wieland, M., Ruiz-Taylor, L., Textor, M., and Brunette, D. M. (2001) Characterization of titanium surfaces. In Titanium in Medicine: material science, surface science, engineering, biological responses and medical applications (Brunette, D. M., Tengvall, P), pp. 87-144, Springer Verlag, Heidelberg and Berlin.

Wahlgren, M. and Arnebrant, T. (1991) Protein adsorption to solid surfaces. Trends in Biotechnol., 9, 201-208. 